Corte y conexión. Montaje y forma musical en Canope, de Claude Debussy

Luis Menacho

Armiliar (N.우), e015, mayo 2019. ISSN 2545-7888

https://doi.org/10.24215/25457888e015

http://papelcosido.fba.unlp.edu.ar/ojs/index.php/armiliar

Facultad de Bellas Artes. Universidad Nacional de La Plata

\title{
Corte y conexión Montaje y forma musical en Canope, de Claude Debussy
}

\author{
Cut and Connection \\ Montage and Musical form in Claude Debussy's Canope
}

\author{
Luis Menacho \\ menacho.luis@gmail.com \\ Facultad de Bellas Artes. Universidad \\ Nacional de La Plata. Argentina \\ Recibido: 7/10/2018 \\ Aceptado: 25/2/2019
}

\begin{abstract}
Resumen
El artículo indaga en las técnicas de montaje elaboradas por el cine, como un procedimiento para la organización formal en la música. A partir de fragmentos heterogéneos que se cortan y conectan han resignificado la forma y el tiempo musical desde las vanguardias del pasado siglo XX. Se analiza el caso del preludio Canope, número diez del segundo libro de Claude Debussy y la incidencia de su concepción musical para nuevas poéticas.
\end{abstract}

\section{Palabras clave}

Montaje; heterogeneidad; mixtura; post tonalidad; tiempo musical

\begin{abstract}
The article explores the assembly techniques elaborated by the cinema as a procedure for the formal organization of music. From heterogeneous fragments that are cut and connected, they have resignified the musical form and time since the avant-garde movements of the 20th century. The case of the Canope prelude, number 10 of Claude Debussy's second book and the incidence of his musical conception for new poetics is analyzed.
\end{abstract}

\section{Keywords}

Montage; Heterogeneity; Mxture; Post tonality; Musical time 
"La música no es solamente asunto de músicos en la medida en que vuelve

sonoras fuerzas que no lo son y que pueden ser más o menos revolucionarias, más

o menos conformistas, como por ejemplo

la organización del tiempo.»

Gilles Deleuze (2015)

1 El caso paradigmático lo constituye el piano. Un instrumento musical alegórico donde se fusionan los más altos estándares del desarrollo de la técnica. Producto de la revolución industrial, tiene su correlato en el instrumento musical que cifra la mayor complejidad armónica de la música europea de tradición escrita. Además de tener un «aura» en tanto mercancía, señala la pertenencia a la posición social de las clases sociales altas. Parte del mobiliario burgués decimonónico, fue al mismo tiempo el instrumento doméstico de acceso y de reproducción de la música durante mucho tiempo.
La consolidación de la técnica hacia fines del siglo XIX produjo la irrupción de nuevos instrumentos y soportes para la creación artística. En la composición musical lo vemos en el desarrollo y el perfeccionamiento del piano, ${ }^{1}$ al tiempo que esa técnica permitió la posibilidad de nuevas disciplinas artísticas como la fotografía y, años más tarde, el cine. El invento del cinematógrafo a fines del siglo XIX por los hermanos Lumière fue toda una sensación en Paris $y$, desde allí, su propagación a diversas partes del mundo; numerosos curiosos se acercaban a observar el nuevo invento. Las primeras películas rodadas sorprendían a los parisinos al mostrar por primera vez la imagen en movimiento, no sin acompañarlas con asombro y también con cierto temor. Una nueva era comenzaba y con ella la gestación y la consolidación paulatina de una industria cultural que se expandiría a lo largo de todo el siglo XX llegando a nuestros días.

A la vez, esos nuevos dispositivos técnicos precisaron elaborar nuevos procedimientos compositivos para la creación artística. Esto es lo que ocurrió con el incipiente cinematógrafo, la necesidad de reflexionar acerca de sus condiciones de producción trajo consigo el concepto de montaje, elemento central en la producción cinematográfica que además tiene resonancias en otras disciplinas artísticas. Veremos en las páginas que siguen, qué ocurrió con la música, tomando el caso de un preludio de Claude Debussy.

Comencemos por el cine, uno de los directores más importantes en ese momento, Sergei Einsestein [1923] (1974) desarrolla los mecanismos de montaje de atracciones en el cine como un conjunto de procedimientos específicos de la disciplina. Con ellos, sostiene, el director somete al público a un conjunto de experiencias sensoriales y psicológicas con el objetivo de provocarle un choque emotivo. En palabras del cineasta:

[...] [son] los posibles principios de construcción como «construcción activa» (del conjunto de la producción). En vez del «reflejo» estático de un acontecimiento, con todas las posibilidades de actividad encerradas en los límites de la acción lógica del acontecimiento, avanzamos a un nuevo plano: el libre montaje de atracciones independientes (dentro de la composición determinada y los lazos argumentales que mantienen 
2 En los comienzos del cine los directores se servían de la música para organizar los planos de acuerdo al ritmo de cambio -armónico, gestual o fraseológico, etcétera- para coordinar el devenir temporal de la cinta. Cine y música comparten, muy íntimamente, una relación cooperativa con la organización del tiempo. unidos los actos de influencia) arbitrariamente escogidos; todo ello con el propósito de establecer ciertos efectos temáticos finales: esto es el montaje de atracciones (Einsestein, 1974, p. 170).

Años más tarde, Andrei Tarkovsky (2016) sostendrá que el montaje es un principio aplicable a todas las artes, casi su condición necesaria, en términos de reunión y ensamblaje de fragmentos de materiales para la consecución de una forma.

Es patente que el montaje existe en todas las artes. Como sucesión y reordenación que necesariamente tiene que hacer el artista. Sin ese proceso no puede existir arte alguno. Ahora bien, el montaje cinematográfico sí que tiene algo específico, que es la coordinación del tiempo fijado en cada una de las partes que se han rodado. Montaje es unir partes mayores y más pequeñas de una película, partes con tiempos diferentes. Sólo su unión aporta una nueva sensibilidad (p. 143). ${ }^{2}$

De este modo, el cineasta ruso se opone a la mirada de Einsestein a propósito de la primacía del montaje como concepto determinante de la praxis cinematográfica, conocido posteriormente como cine de montaje. En su lugar, le dará primacía al ritmo, derivado de la temporalidad que propone cada plano.

El ritmo queda más bien constituido por la presión temporal dentro de los planos. Yo estoy profundamente convencido de que el ritmo es el elemento decisivo - el que otorga la forma- en el cine. No lo es, por otra parte, el montaje, según se suele creer (Tarkovsky, 2016, p. 143).

La diferencia que señala Tarkovsky acerca de la importancia relativa del montaje frente al ritmo, se apoya especialmente en las experiencias de las poéticas de la segunda posguerra: cita el caso de películas sin cortes donde se muestra el flujo del tiempo, como Sleep (1963), de Andy Warhol. En el cine de Tarkovsky la idea de movimiento dentro de un plano y el fluir de la temporalidad es una de sus marcas distintivas. Así, del movimiento de los juncos se puede reconocer el carácter de la corriente del río, la presión del agua. Del mismo modo, el proceso vital que la toma reproduce en su movimiento informa del movimiento del tiempo (Tarkovsky, 2016).

Asimismo, este concepto de montaje, en tanto procedimiento, podemos constatarlo en la composición musical a partir de materiales heterogéneos, ritmos y temporalidades diversas. Estos son reunidos desde un principio de atracción -o podríamos decir también, de oposición o repulsión-, y ponen en primer plano el acto del cut and paste (cortar y pegar) o como decía Gerardo Gandini en sus clases, cómicamente: Connecticut. ${ }^{3}$ El compositor 
3 Literalmente, lo traducía como cortar y conectar; es decir, el propio acto manual del montaje. En su séptima sonata, por poner un caso, durante el proceso de composición los materiales se encontraban en múltiples fragmentos escritos en papelitos, los cuales ordenaba de diferentes modos probando la mejor posibilidad para conseguir la macroforma final de la obra.

4 Como sostiene Peter Burger (2000), en su lectura del fragmento y la alegoría benjaminiana en las vanguardias. "Lo alegórico arranca un elemento a la totalidad del contexto vital, lo aísla, lo despoja de su función. La alegoría es, por tanto, esencialmente un fragmento, en contraste con el símbolo orgánico [...] La falsa apariencia de la totalidad desaparece». «Lo alegórico crea sentido al reunir esos fragmentos aislados de la realidad. Se trata de un sentido dado, que no resulta del contexto original de los fragmentos».

5 Vemos su oposición a los tópicos más característicos del Romanticismo «[...] esa escuela romántica a la que debemos nuestro Berlioz, tan enamorado del colorido romántico que se olvida a veces de la música; Wagner, gran empresario de símbolos, y más nuestro Richard Strauss, de imaginación tan curiosamente organizada por el romanticismo. Weber puede enorgullecerse de tal descendencia y consolarse con la gloria de los hijos de su genio de que no se toquen nada más que las oberturas de [sus] obras" (Debussy, 1945, p. 59).

6 Canope es una urna funeraria del antiguo Egipto. Debussy coloca el título - como en todos sus preludios - al final, como una suerte de develamiento posterior de ese universo evocado.

7 Este tipo de escritura de movimiento paralelo de las voces -típicamente debussyana- también es conocida como parafonías. Debussy las elabora a partir del movimiento paralelo de octavas y quintas de los comienzos de la polifonía medieval del ars antiqua.

8 La doble enunciación es una forma de la variación utilizada por Debussy que implica la repetición mínimamente variada de un material. A diferencia de la variación mínima de los vieneses esta no se restringe a un material temático para un desarrollo, sino que, por el contrario, es un procedimiento aplicado a objetos sonoros en una forma no finalista. desde el siglo XX dispone de un nuevo recurso, cortar y conectar fragmentos para la organización macroformal. El compositor devino, como ocurrió previamente con el cine, en un montajista al trabajar con materiales musicales heterogéneos y fragmentarios. Estos rasgos serán los más importantes desde las vanguardias ${ }^{4}$ de comienzos de siglo XX. Luego de la supresión de la tonalidad por parte de los compositores de la escuela de Viena o la disolución de la tonalidad como veremos con Debussy, el fragmento es uno de los rasgos más importantes de todo material sonoro.

\section{Canope}

El conjunto de preludios para piano divididos en dos volúmenes fue compuesto por Claude Debussy en el transcurso de cuatro años: el primero entre 1909-10 y el segundo en 1913, año en que se estrenó también Le sacre du printemps de Igor Stravinsky. Este conjunto de preludios constituye un faro para la literatura pianística del siglo XX no solo por la riqueza de ideas musicales que contiene, sino también por la elaboración de un universo sonoro completamente nuevo. Como podemos ver en Canope, número 10 del segundo libro, asistimos a uno de los preludios más paradojales y extraños. Lleno de sutilezas - Debussy fue un compositor extremadamente detallista en lo que atañe a la notación de sus obras- nos abre un mundo sonoro completamente nuevo, alejado de toda retórica romántica. ${ }^{5}$

Canope, ${ }^{6}$ ya desde su título, nos señala lo exótico y lo arcano. Lo podemos observar en la primera sección [Figura 1], con la textura a la manera de un organun paralelo ${ }^{7}$ - parafonías- en un campo armónico de Re dórico-eólico (si-sib) y su posterior desvío - corte- con los acordes de Lab - Mib y Solb, que conectan cromáticamente las voces con la polaridad del acorde de rem para la doble enunciación ${ }^{8}$ de la soprano del primer material dos octavas más grave y en octavas (compases 5-6). A continuación, en el compás 7 , se genera una nueva juntura con la dominante Re con séptima menor que es negada con la séptima mayor (do\#) desde donde se despliega la línea cromática en doble bordadura superior e inferior de la nota polar re.

La coexistencia de do y do\# nos señala una idea nueva: ya no es solo un acorde de séptima de dominante, sino una pequeña constelación sonora vertical organizada con las notas precedentes, no reductibles a un acorde tonal. Desde allí vemos cómo continúa una pequeña línea que despliega un campo cromático (do\#, mib, fa, mi, re) como un arabesco que forma un ámbito de cluster. El material en estos pocos compases no puede definirse en términos de tematicidad melódico-armónica ni menos aún como organización armónica 
tonal. Por el contrario, asistimos a la emergencia de un material definido como dos objetos sonoros - la textura de organun y el acorde de séptima mayor-menor con su arabesco, todo organizado a partir de un campo armónico de re dórico-eólico en la parafonía y luego en una polaridad sobre re como acorde y como nota en la línea.

$-\mathrm{X}$.

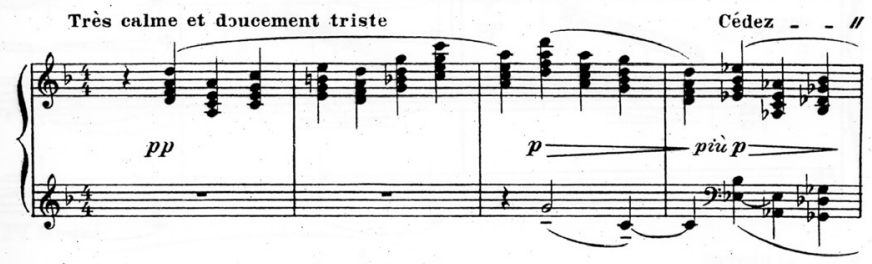

Mouvt

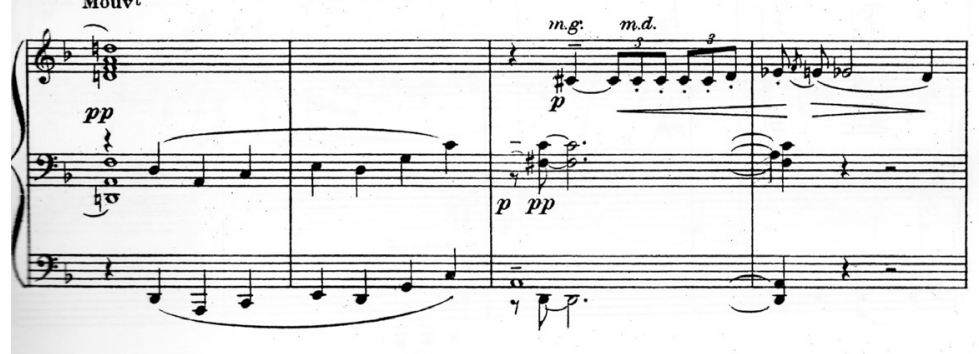

Figura 1. Canope (1913), Claude Debussy. Compases 1-8

Un objeto sonoro será, desde esta perspectiva, una nueva concepción del material, entendiéndolo como un elemento fragmentario privado de un centro hacia una organización temática y su consecuente elaboración motívica. El objeto sonoro no remite a un tema a la manera de las formas clásicas - pensemos en la forma sonata o el tema con variaciones donde el tema gobierna todas las variaciones o el desarrollo-; por el contrario, es un material descentrado y fragmentario. La variación sin centro que pone en juego la doble enunciación, como su forma de variación privilegiada, es una multiplicidad sin una unidad que gobierne a priori la obra; de allí que no posee una forma preexistente, teleológica o finalista, sino que la descubre en su propia trayectoria. En otras palabras, es en el devenir resultante del despliegue de los materiales, que la temporalidad de la obra encuentra su forma sonora. Quizá por esto Debussy coloca los títulos al final de cada uno de los preludios, la forma en su música es un trayecto que adquiere su configuración desde una mirada retrospectiva. 
9 Aquel hombre moderno caminante de las calles de París a comienzos del siglo XX y descripto por Walter Benjamin en el capítulo "El flanêur», de El libro de los pasajes (2005).
Como sostiene Gisèle Brelet (1957) en su libro Estética y creación musical:

En Debussy se opera la unión íntima de la forma temporal y de la forma sonora, estando la forma temporal como descubierta en lo íntimo de la forma sonora misma y pareciendo nacer espontáneamente de ella misma (s.p.).

\section{Y más adelante agrega:}

La experiencia temporal de Debussy se confunde con su intuición de las relaciones sonoras; y la delicadeza de sus percepciones auditivas, volviendo inútil el habitual procedimiento temático, engendra desarrollos que surgen directamente de las mismas armonías. A los que reprochan a la música impresionista su ausencia de forma, es preciso responder que en música tal la forma no es ya simetría aparente y grosera, sino más sutil y secretamente que en la música clásica, se disimula en las propias relaciones sonoras; y su sutileza expresa la docilidad con la cual sabe hacerse la sierva de la armonía. Si en el desarrollo temático del clasicismo las sonoridades se subordinan a las formas temporales preestablecidas, en el impresionismo es en ellas mismas y en sus afinidades naturales donde reside su principio de desarrollo (Brelet, 1957, s.p.).

Como nacida de la subjetividad propia de un flanêur, ${ }^{9}$ la forma musical en Debussy no implica el trazado de un recorrido previo. Por el contrario, en esa aparente errancia se esconde la multiplicidad de las sensaciones que percibe a cada momento. En la escucha de Canope asistimos a la captación del devenir de los materiales y sus posibilidades de variación. Ese devenir nos lleva finalmente a encontrar la forma como resultado de la trayectoria desplegada en el tiempo. No como esquema a priori, sino, antes bien, como tiempo vivido. Como sostiene Brelet, la forma temporal y la forma sonora se encuentran íntimamente entrelazadas.

La idea de una armonía tonal también es resignificada, puesto que los materiales provenientes del sistema armónico tonal o de la modalidad - por caso el re menor modal del organun o el acorde de re dominante- se encuentran modificados en la irrupción de una sonoridad que los niega - como la doble séptima (do-do\#) - y que desdibuja toda cualidad de dominante al romper el tritono (fa\#-do). Es por esto que, de la mano del objeto sonoro, la idea de una armonía tonal y su funcionalidad pierden ese centro gravitacional organizador de todos los niveles de la estructura tonal. En su lugar, se impone una nueva idea de lo vertical: la constelación. Esto es, una configuración vertical que no responde necesariamente a la primacía de un ordenamiento armónico desde 
10 Veamos el caso de las aglomeraciones verticales que escribe Edgard Varése en obras como Octandre (1923), Amèriques (1918-21), Arcana (1925-27) o Integrales (1923-25), pocos años después.

11 Primero, con el atonalismo libre y, luego, con la organización de la disonancia que propone el dodecafonismo. un sonido fundamental - como el caso de los acordes derivados de una escala en la tonalidad-. Al contrario, en la constelación parecieran flotar los sonidos emergentes deslindados de un centro gravitacional atractivo, a la manera de la modalidad o la tonalidad. Se trata de una coexistencia que posibilitará —en lugar de un ordenamiento desde la serie de los armónicos- arribar a espectros más complejos e incluso inarmónicos. ${ }^{10}$

Esta pérdida de la funcionalidad lo acerca asimismo al concepto que propone Arnold Schoenberg (1911) en su Tratado de la armonía respecto a los acordes errantes, los cuales derivan de la concepción de acordes provenientes de la tonalidad, pero emancipados de la relación tensión-distensión, lo que equivale a la funcionalidad armónica. En ambos casos, la suspensión de la síntesis dialéctica que se pone en juego entre estos principios opuestos -representados por los acordes de I y $\mathrm{V}$ grados, respectivamente- nos descubre en forma negativa la preeminencia de la tensión y la evitación de una resolución y reposo. En ese sentido, la dialéctica negativa adorniana nos señala esto: la suspensión de la Aufhebung en términos de superación o síntesis hace permanecer a los términos en un estado de tensión y ambigüedad sin resolución, configurando un nuevo horizonte de sentido $y$, consecuentemente, una nueva poética. Si bien Schoenberg arriba a los acordes errantes desde el desarrollo último de los materiales de la tonalidad y Debussy hace lo propio con los objetos sonoros desde el concepto de mixtura - es decir la mezcla de materiales de diversa procedencia-, en ambos casos se hace patente la imposibilidad de una síntesis dialéctica y, a la vez, se configuran dos maneras de responder a la crisis del sistema armónico tonal en las primeras vanguardias del siglo XX.

Es por esta razón que resulta importante destacar la diferencia entre la supresión de la tonalidad por parte de Schoenberg y los vieneses, ${ }^{11}$ frente a la disolución de la tonalidad por parte de los franceses, especialmente Debussy y Erik Satie, pero también Stravinsky. La tonalidad al mostrar su agotamiento hacia fines del siglo XIX se reveló como finita, lo cual habilitó el juego con la mixtura, es decir, el poder mezclar sus elementos con otros materiales posibles como las texturas parafónicas, los modos eclesiásticos, las escalas pentatónicas y hexatónicas, etcétera. Desde allí podemos ver cómo ambas soluciones - frente a ese problemaarribaron a la atonalidad -o no tonalidad- desde distintas concepciones y que derivaron en lo post tonal. Una liberó la disonancia y, como correlato necesario, la gramática tonal; la otra mixturó paradigmas con gramáticas diferentes - por eso aquí es clave este concepto de montaje - en pos de la mixtura. El universo de lo modal se resignificó en toda su multiplicidad creadora durante 
el siglo XX, especialmente en las músicas populares de tradiciones urbanas como el jazz y el rock. Por otro lado, la atonalidad exploró formas de organización que van desde el serialismo hasta las múltiples elaboraciones libres del material interválico cromático. En todo caso, son certeras las palabras de Stravinsky (1952), para quien la tonalidad «[...] no ha tenido fuerza de ley sino entre músicos de un periodo bastante más corto de lo que se acostumbra imaginar, ya que no comprende más que a los de mediados del siglo XVII a la mitad del siglo XIX» (p. 48).

Es por esto que para Debussy y Stravinsky cobra importancia en el nivel macroformal la organización de una polaridad, es decir, de un sonido o un acorde ya no con la primacía macroestructural de una tónica principal, sino como un polo -aunque no siempre con la cualidad de atracción, vale decir-que puntúa y organiza la irrupción de los diferentes materiales. Deslindado de la hegemonía ordenadora vertical y de la posibilidad de organizar la gramática de las tensiones y distensiones propias de la tonalidad, la polaridad asegura los espacios de juntura entre fragmentos. Como afirma Stravinsky (1952): «Lo que nos preocupa, es menos la tonalidad propiamente dicha que aquello que se podría denominar la polaridad del sonido, de un intervalo o aun de un complejo sonoro" (p. 47).

Diversos objetos se concatenan a partir de allí, donde la doble enunciación juega un papel primordial en tanto repetición variada de los fragmentos, los cuales se definen desde una procedencia distinta: elementos provenientes de la tonalidad como una relación I-IV que se repite y acentúa sonidos agregados a la estructura vertical del acorde. En este sentido, el acorde puede ser el objeto sonoro y polar - despojado de las relaciones cadenciales propias de la tonalidad - que se presenta como material para una ulterior elaboración.

12 Es decir, derivados de la constelación sonora vertical.

13 Ese stimmung es entendido como estado de ánimo o, podríamos decir siguiendo a Deleuze, afecto de cada obra (Deleuze \& Guattari, 1993).
[...] el desarrollo debussysta posee una unidad y una continuidad que en manera alguna son menores que las del desarrollo continuado de la música clásica. La diferencia consiste en que en la forma impresionista, las analogías son "atmosféricas» ${ }^{12}$ más bien que estructurales, basadas sobre las asonancias y no sobre esquemas temporales abstractos. La duración está recobrada como la exigencia misma de la materia sonora, y por tal causa ésta, en vez de someterse a una unidad temática exterior, se organiza espontáneamente alrededor de un stimmung ${ }^{13}$ armónico (Brelet, 1957, p. 79).

Observemos lo que nos muestra la segunda figura entre los compases 13 y 19 [Figura 2]. La línea descendente conecta cromáticamente con los objetos acordes de DoM9-Fa79 en una relación I-IV y se repite textual. La voz interior llega al mib y se expande 
dos octavas trasformada en una apoyatura que -mediante la repetición- se transforma en la juntura con el comienzo de la segunda sección (Animez un peu). Este nuevo objeto -ahora como doble apoyatura de las cuartas (re-sol) y apoyadas por el (mib-la) formando un tritono - se expande hacia el registro medio y grave con la trasposición de las apoyaturas y las notas tenidas (do-fa) a (si-mi) junto a un acorde por cuartas de dos tritonos. Introduce, luego, la nota (la) grave como conector para una expansión registral de dos octavas en la mano derecha y la consecuente repetición de la doble enunciación del objeto apoyatura.
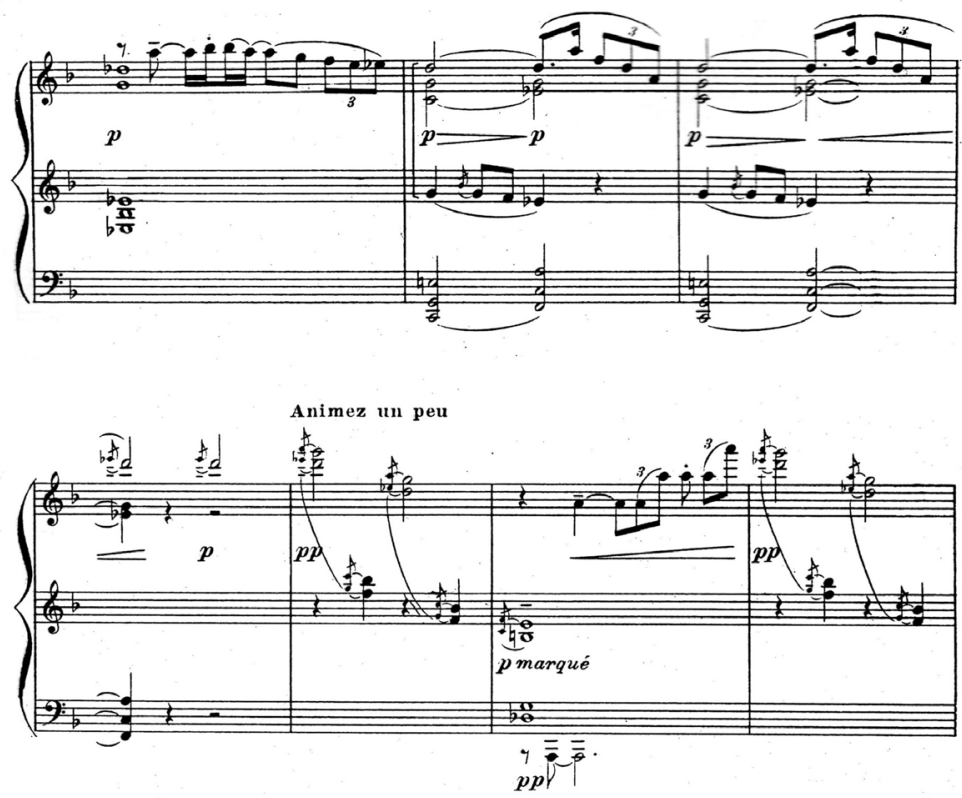

Figura 2. Canope (1913), Claude Debussy. Compases 13-19

Podemos ver cómo los materiales se encuentran desvinculados de una lógica tonal. En lugar de esto, el montaje de elementos diversos es posible gracias a la juntura — como con la nota (la) repetida- que genera atracciones entre los materiales que cohesionan la trama sonora. Corte de una conducta y conexión con una nueva. A la vez, el objeto sonoro en tanto material permite redefinir no solo la relación horizontal-vertical tradicionalmente entendida en términos de lo lineal melódico y lo vertical armónico, sino que al mismo tiempo propone una nueva manera de entender la forma y la temporalidad. 
14 A propósito de Olivier Messiaen Diether De la Motte (1993) señala su trabajo con "El acorde como tema». Esta idea se acerca a un oxímoron puesto que la idea de tema - tal y como lo elaboró el clasicismo- privilegió una textura de monodia con acompañamiento enmarcada en una oposición de figura-fondo: melodía y acorde. Esta idea de una emancipación del fondo comienza a vislumbrarse ya en Beethoven en obras como en la Sonata Op. 53 Walstein, en la exposición con la repetición del acorde de Do mayor, convirtiéndolo casi en un objeto.
Fue ya idea de Debussy desarrollar una composición partiendo exclusivamente de las posibilidades armónicas de la tercera en sus «Tierces alternées» (Preludios II)... Un acorde o un elemento estructural para la construcción de acordes pueden constituir una idea central de una pieza, el tema [...]. Vemos con frecuencia en la música del siglo XX que las ideas son desplazadas como recurso del material por la forma: al compositor no se le ocurren melodías, sino elementos estructurales y posibilidad de construir algo con ellos ${ }^{14}$ (de la Motte, 1993, p. 278).

En la segunda sección [Figura 3] llegamos al clímax de la pieza. La línea cromática ascendente se conecta mediante la nota (sol) a un momento delineado a partir de una figuración de arpegio descendente en fusas y que está constituido por tres pequeñas configuraciones cromáticas, como clusters simétricos alrededor de un eje de segunda menor: a- lab-sol-fa\#; b- re-do\#; c- sib-la-lab. Los extremos a su vez enmarcan una octava lab y anticipan en cuanto a la sonoridad las consecuentes octavas do y luego mib en la doble enunciación de este objeto. Estos tres polos (lab-do-mib) describen a su vez un acorde perfecto mayor de lab.

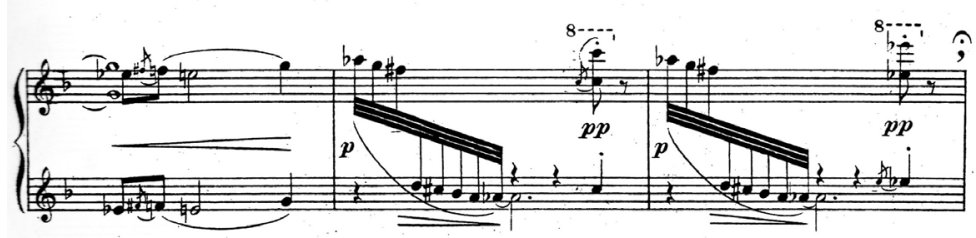

Figura 3. Canope (1913), Claude Debussy. Clímax de la obra al final de la segunda sección

Analicemos el tratamiento que Debussy elabora desde la liberación de la disonancia. En lugar de tomar el cromatismo vinculado únicamente a la relación interválica — como en los vieneses-aquí vemos cómo configura objetos inestables, es decir, elaborados desde la disonancia, como los cromatismos lineales, y otros más estables, como las octavas o los acordes tríadas. Resulta de interés destacar no solo la irrupción de este arpegio cromático en rápida figuración, sino además cómo esto incide en la escucha de la organización temporal de la obra, puesto que es el momento de mayor ambigüedad en la percepción de la pulsación. El rápido arpegio que mantiene la última fusa como nota tenida sobre tres tiempos hasta la articulación del cuarto tiempo con la octava, desdibuja muy sutilmente la percepción del pulso. Al haber partido de la correspondencia de los ataques en tiempos de negra coincidentes con los valores unitarios de la pulsación - como vimos al comienzo de la obra con el organum— podemos establecer una 
15 A su vez, tampoco hubieran sido posibles poéticas como la de Morton Feldman, su búsqueda de componer con el tiempo -es decir, utilizando el tiempo como materialy su aspiración de escribir lienzos en el tiempo, borrando los límites entre pintura y música.
16 ¿No sería mediante el montaje como se funde en la duración pura la heterogeneidad máxima haciendo patente la diferencia? trayectoria hasta este momento donde la escritura desdibuja por completo la matriz organizadora del tiempo musical, dejando desnuda la duración y su cuantificación. En otras palabras, el tiempo queda en suspenso.

La cuestión sería saber en qué consiste este tiempo no pulsado, este tiempo flotante, casi lo que Proust llamaba «un poco de tiempo en estado puro». El primer rasgo de este tiempo, el más evidente, es que se trata de una duración, es decir, de un tiempo liberado de la medida, sea regular o irregular. Un tiempo no pulsado nos pone, pues, en presencia de una multiplicidad de duraciones heterócronas, cualitativas, no coincidentes, no comunicantes: no se camina siguiendo un compás, así como no se nada o vuela siguiendo un compás (Deleuze, 2015, p. 13).

Caminar haciendo patente la duración, errando entre la multitud, intuir en el tiempo flotante el tiempo en estado puro, es uno de los mayores aportes de las primeras vanguardias a las músicas del siglo XX hacia nuestros días; una concepción clave para la música concreta y electrónica, por casos, sin la cual no hubiera sido posible imaginarlas en las vanguardias de la segunda posguerra. ${ }^{15}$

El tiempo no pulsado no es solamente un tiempo liberado de la medida, es decir, una duración; tampoco es sólo un nuevo procedimiento de individuación, liberado del tema y del sujeto, sino que, finalmente, es el nacimiento de una materia liberada de la forma (Deleuze, 2015, p. 23).

O como sostiene Henri Bergson (1999), a propósito de la duración:

[...] la pura duración bien podría no ser sino una sucesión de cambios cualitativos que se funden, que se penetran, sin contornos precisos, sin tendencia alguna a exteriorizarse unos con relación a otros, sin parentesco alguno con el número: sería la heterogeneidad pura ${ }^{16}$ (p. 79).

Hacia el final de pieza, vemos en la figura precedente [Figura 4] la reexposición del material de escritura parafónica -organum-y la discontinuidad modal del re (corte) hacia la progresión Mib menor, Sib menor, Lab menor y la nueva yuxtaposición con Mi menor y La mayor, para culminar con una cadencia plagal de fa menor-do mayor con novena agregada en la soprano. Finalmente, la coda desde la nota (la) descendiendo hacia la nota polar (re) en un ámbito de quinta justa; siempre sobre el pedal del acorde de Do9 a la manera de un órgano. Aquí no asistimos a una reexposición en términos de forma ternaria reexpositiva sonatística, puesto que no hay ninguna necesidad tonal o de desarrollo temático que así 
17 Dos preludios aluden a la muerte. Des pas sur le neige (Pasos sobre la nieve) 一número 6 del libro I- culmina con el descenso en todo el registro en un correlato sonoro hacia el descenso final; como el trayecto de encontrar la muerte. En Canope se la alude mediante un objeto - la urna funerariay se revela como algo estático, separado de una experiencia inmediata, distante. Quizá por eso la obra pareciera estar en un perpetuo suspenso. La géstica de sus materiales está escrita de manera acéfala indicándonos algo que -desprovisto del contacto con la tierra- pareciera ya no tener peso. lo requieran. En su lugar, la recapitulación de los objetos del comienzo funciona apenas como un marco que encuadra el decurso temporal de los materiales y su evolución subsiguiente. La obra en este momento final se detiene, culminando así la trayectoria de su arco formal. ${ }^{17}$
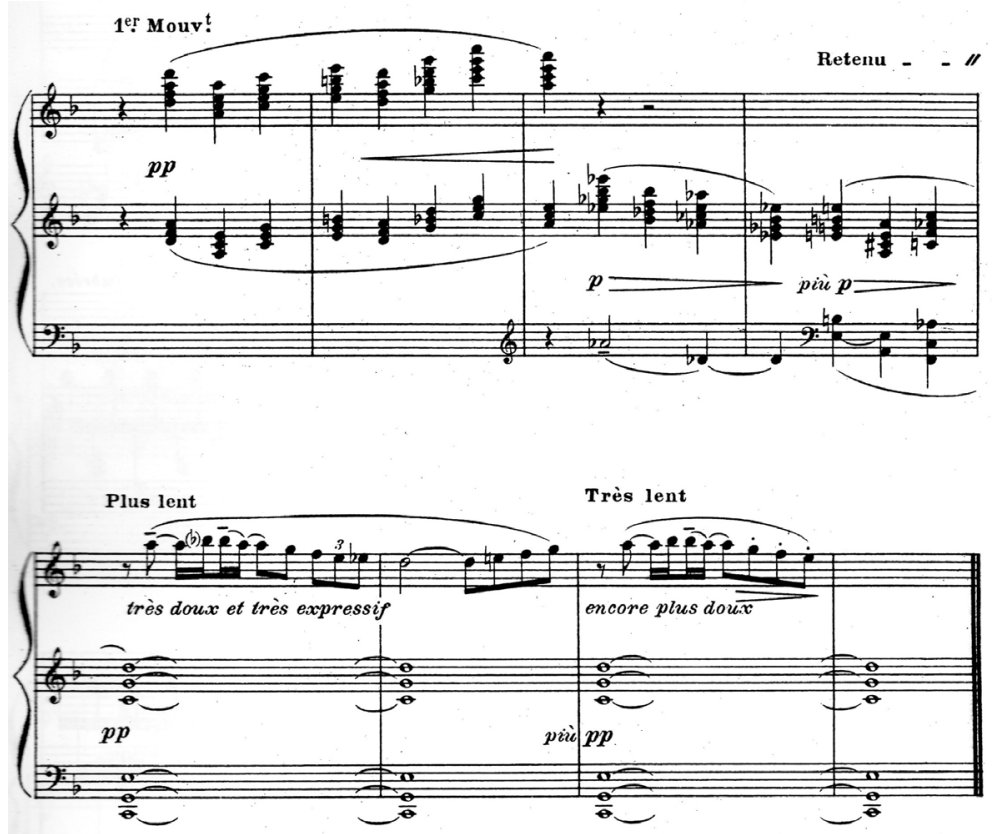

Figura 4. Canope, compases finales (1913), Claude Debussy

\section{Conclusiones}

Hemos intentado describir algunos elementos significativos que encontramos en la poética de Claude Debussy a partir del análisis del preludio Canope. La resignificación de los materiales en tanto objetos sonoros compuestos de materias heterogéneas constituye un Cuerpo sin órganos (CsO), es decir, una unidad irreductible a lo Uno, a una tematicidad que otorgue sentido a todo el conjunto de manera unívoca. Esto se corresponde con lo que postulan Gilles Deleuze y Félix Guattari en su clásico texto «Rizoma» [1980] (2000) en el que elaboran, desde caracteres tomados de la botánica, la oposición entre el árbol, como configuración en la cual lo Uno deviene hacia lo múltiple -el tronco hacia las ramas-, y el rizoma, donde no hay raíz originaria sino que el tallo prolifera haciendo bulbos múltiples. En la música clásico romántica podemos ver que el árbol se corresponde con las grandes formas como 
18 Al mismo tiempo, el concepto de constelación habilitó el desarrollo en la composición de otros parámetros del sonido como la articulación, la intensidad, la rítmica y especialmente el timbre en las poéticas del siglo XX; como es el caso de la música concreta instrumental propuesta por Helmut Lachenmann. la sonata o el tema con variaciones. En ellas, desde uno o varios materiales temáticos se genera toda la diversidad sonora.

Por el contrario, en el rizoma, y desde el siglo XX — como hemos podido ver en Canope-, la forma se genera desde los múltiples fragmentos en permanente descentramiento, sin unidad a priori, proliferando para encontrar su forma final como trayectoria retrospectiva.

De la organización que suscitó la tonalidad, con la dualidad de la tensión y el reposo, las modulaciones y su tratamiento específico de la disonancia, asistimos a la configuración de una constelación sonora como correlato de la expansión de los campos armónicos de una organización vertical, ahora no reductible a los criterios de consonancia-disonancia heredados por la tradición. En su lugar, los sonidos de una constelación son emergentes solo de la relación entre sus intervalos. ${ }^{18}$ De este modo, la organización de los objetos sonoros en el tiempo está dada por la multiplicidad que permite, mediante el montaje, la mixtura de materiales diversos sometidos a un procedimiento de juntura (corte y conexión) de elementos que operan en atracción (similitud-continuidad) o repulsión (diferencia-discontinuidad).

El ordenamiento que resulta del montaje de materiales se sirve de conceptos como el de polaridad y permite organizar y concatenar complejos sonoros con mayor grado de estabilidad o inestabilidad, en una delicada relación de fuerzas que ponen en juego una amplia gama de matices y posibilidades expresivas. Es así como el timbre, el registro, la dinámica, la duración y el modo de ataque son variables que pueden condicionar y reconfigurar por completo los materiales sonoros.

Por último, la paulatina emancipación de la pulsación nos convoca a experimentar la duración y el tiempo como cualidad. Es decir, más allá de la mensuración y la cuantificación del tiempo musical que se originó en la Europa medieval y que permitió el desarrollo de la polifonía, en diversas poéticas del siglo XX creció la inquietud de liberar al tiempo y a la forma de la cuantificación y la medida - como sostiene Brelet, dejando de lado esas simetrías aparentes de músicas en el pasado-. Por el contrario, la temporalidad de la forma en Debussy y la concepción del tiempo musical que comienza a poner en obra, descubre, como un caminante que mirando atrás el trayecto recorrido, observa y reencuentra los senderos de lo que fue su itinerario, su forma final. Una experiencia nueva del tiempo se inaugura con esta poética, dando lugar a variadas músicas desde el siglo XX hasta nuestros días. 


\section{Referencias}

Benjamin, W. (2005). El flanêur. En El libro de los Pasajes (pp. 422-425). Madrid, España: Akal.

Bergson, H. (1999). Ensayo sobre los datos inmediatos de la conciencia. Salamanca, España: Sígueme.

Brelet, G. (1957). Estética y creación musical. Buenos Aires, Argentina: Hachette.

Bürger, P. (2000). Teoría de la vanguardia. Barcelona, España: Península.

De la Motte, D. (1993). Armonía. Barcelona, España: Labor.

Debussy, C. (1913). Préludes 1e et 2e livre. Parías, Francia: Durand \& Cte editeurs.

Debussy, C. (1945). El señor croche. Antidilettante. Buenos Aires, Argentina: Anaquel.

Deleuze, G. [1978] (2015). El tiempo musical [Resumen de las conferencias que se dieron en el Institut de Recherche et Coordination Acoustique/Musique (IRCAM)]. México: El latido de la máquina. Recuperado de https://issuu.com/ellatidodelamaquina/docs/latidodemaquina_01_ gilles_deleuze

Deleuze, G. y Guattari, F. [1980] (2000). Mil Mesetas. Capitalismo y esquizofrenia. Valencia, España: Pre-textos.

Deleuze, G. y Guattari, F. [1991] (1993). ¿Qué es la filosofía? Barcelona, España: Anagrama.

Einsestein, S. [1923] (1974). El sentido del cine. Buenos Aires, Argentina: Siglo Veintiuno.

Schoenberg, A. [1911] (1974). Tratado de la armonía. Madrid, España: Real Música.

Stravinsky, I. (1952). Poética musical. Buenos Aires, Argentina: sin datos.

Tarkovsky, A. (2016). Esculpir en el tiempo. Madrid, España: Rialp.

Warhol, A. (Director). (1963). Sleep [Película]. Recuperado de https:// www.youtube.com/watch?v=KaiEM2lUoZg 